\title{
Una lectura nacionalista del pasado clásico: la Historia de Roma de Ernesto Palacio
}

\author{
Mariano Sverdloff ${ }^{1}$
}

Resumen. Para los escritores de la derecha nacionalista argentina, el pasado clásico ocupa un lugar central. La Historia de Roma (1939) de Ernesto Palacio no es la excepción: este pequeño texto, que debía servir como un manual escolar, es una muestra del modo en el que el nacionalismo argentino imaginaba, a partir de los debates históricos y políticos más contemporáneos, la tradición grecolatina. La relectura de esta tradición asimismo, implicaba postular una cierta imagen de «Occidente» y legitimar la traducción de textos de las literaturas europeas modernas. El objeto pues, de este trabajo, es analizar esta invención del pasado clásico por parte de Ernesto Palacio y de las derechas nacionalistas, y discutir brevemente por qué a partir del retorno a la democracia en 1983 las derechas argentinas dejan de recurrir a este uso político de la tradición grecolatina.

Palabras clave: Nacionalismo; antigüedad clásica; derechas; Argentina; traducción.

\section{[en] A Nationalist Reading of the Classical Past: the Historia de Roma of Ernesto Palacio}

\begin{abstract}
For the writers of the Argentine nationalist right, the classical tradition is a crucial matter. Historia de Roma (1939) by Ernesto Palacio is no exception: this small text, a school manual, is an example of the way in which Argentine nationalism imagined the Greco-Roman tradition in order to discuss contemporary politics and history. The appropiation of the classical legacy allowed them to postulate a certain image of «the West» and to legitimize their own translations from modern European literatures. The purpose of this article is to analyze this invention of the classical past made by Ernesto Palacio and other nationalist writers, and to briefly discuss why, since the return of democracy in 1983, the Argentine rigth has almost completely stopped to refer to Greco-Roman tradition.
\end{abstract}

Keywords: Nationalism; classical antiquity; far right; Argentina; translation.

Sumario. 1. Usos de los clásicos. 2. Un uso intenso de la antigüedad clásica. 3. Disolución del uso de la referencia clásica.

Cómo citar: Sverdloff, M. (2020) Una lectura nacionalista del pasado clásico: la Historia de Roma de Ernesto Palacio, en Anales de Literatua Hispanoamericana 49, 17-27.

\section{Uso de los clásicos}

Quisiera comenzar este artículo con una breve advertencia metodológica: voy a referirme a los "usos" de los clásicos, y no a conceptos tales como "tradición" o "legado". En el campo del estudio de las recepciones de la cultura clásica, la categoría de "tradición" suele implicar toda una serie de sobreentendidos, que evocan nociones tales como organicidad, arborescencia y origen. Thierry Maulnier, intelectual francés "no conformistas" (Loubet del Bayle 2001) estrechamente ligado a las derechas de los años '30, da una definición que, desde mi punto de vista, es el perfecto resumen de este movimiento de esencialización. En un libro donde narra de forma idealizada su viaje a Grecia, Cette Grèce où nous sommes nés (1964), dice Maulnier: "Grecia es la Europa de Europa" (Maulnier 1964:6) lo cual podría parafrasearse como "Grecia es

\footnotetext{
Facultad de Filosofía y Letras, Universidad de Buenos Aires-CONICET. Buenos Aires. Argentina.

Email: marianosverdloff@gmail.com

Este trabajo es parte del Proyecto de Investigación Plurianual "La legitimación del escritor moderno en América Latina y Europa. Polémicas, operaciones, representaciones" (CONICET /UBA).

Asimismo, agradezco a Boris Matías Grinchpun, con quien he discutido las ideas de este trabajo.
} 
el origen del origen". En la misma línea se inscriben las metáforas de raíz etimológicas, basadas en verbos como el griego didomi y el latín trado, a las que suelen apelar los defensores de la "tradición clásica" (a ellas por ejemplo recurre Alberto Caturelli, un filósofo tomista argentino, a quien volveré a mencionar más abajo, en su Historia de la filosofía en la Argentina, 1600-2000 [Caturelli 2001:41]). Propongo hablar de un "uso" de los clásicos, entonces, y no de "tradición" en términos de continuidad. En otro trabajo planteé una reformulación -de forma un poco paródica, si se quiere- de la máxima de la filología recentiores deteriores (Sverdloff 2017). Esta frase que, como se sabe, pertenece a la lógica del cotejo de las variantes y la construcción del stemma codicum, significa que los códices o las lectiones son peores ("deteriores") cuanto más recientes ("recentiores"). Yo propuse, por el contrario, como máxima heurística "deteriores significatiores", esto es, la idea de que cuanto más maltrata o reformula un texto sus fuentes clásicas, este "uso" se torna más evidente o significativo, y más debe hacernos pensar sobre la productividad que cobra el texto clásico en su nuevo contexto.

Es a partir pues de este marco metodológico que he venido analizando el uso de los clásicos que hace el "nacionalismo de derecha" argentino ${ }^{2}$. Como se sabe, el nacionalismo ha practicado diversas formas de traducción y apropiación de autores extranjeros, antiguos y modernos. Este fenómeno ha sido analizado, desde una perspectiva literaria, para mencionar solamente algunos trabajos, por Edgardo Dobry en El linaje de Hércules (2010), o por María Teresa Gramuglio en los artículos reunidos en Nacionalismo y cosmopolitismo (2013); también las relaciones transnacionales de las derechas han sido abordadas, desde enfoques históricos muy diversos, por ejemplo por Federico Finchelstein (2010), Ernesto Bohoslavsky (2018) o Juan Luis Besoky (2019), entre otros. En la descripción de esta dinámica, quizá una de las dimensiones menos exploradas de forma sistématica por la crítica -si bien no faltan interesantes observaciones como las que hace el antedicho Dobry o Fernando Devoto (2006:188, por ejemplo)- sea el uso del pasado clásico a los efectos de proponer una "tradición verdadera", que fundaría la supuesta unidad "hispano-criolla" de la nación argentina. En efecto, si bien los autores europeos a los que más recurre la tradición del nacionalismo de derecha son aquellos que critican la revolución de 1789 y su legado democratizador y universalista (Charles Maurras, Maurice Barrès, Numa Fustel de Coulanges, para mencionar solamente algunos exponentes de la influyente tradición francesa), también encontramos que la relectura de la historia y la literaturas clásicas ocupan un lugar central para intelectuales como Julio Irazusta, Carlos Ibarguren o Ernesto Palacio. Historia de Roma (1939), del mencionado Palacio, es un excelente ejemplo de esta relectura del pasado clásico. Me propongo, pues, a través del análisis de este texto pedagógico, acercarme al modo en el que el nacionalismo de los '30 y '40 hizo dialogar su interpretación de Grecia y Roma con nociones tales como "comunidad" y "tradición", a los efectos de integrar el modelo clásico a la disputa cultural y política. Finalmente, y a modo de conclusión, intentaré ofrecer algunas hipótesis provisionales acerca de los motivos de la disolución de este uso de la tradición clásica en el campo de las derechas argentinas.

\section{Un uso intenso de la antigüedad clásica}

Escrito bajo la forma aparentemente anodina de un manual escolar, Historia de Roma de Ernesto Palacio retoma, sin embargo, muchos de los tópicos centrales de Catilina: contra la oligarquía, de 1935. En efecto, la advocación a las autoridades (Theodor Mommsen, Jules Michelet, Victor Duruy, Max Weber, Guglielmo Ferrero), que Palacio declara seguir de cerca o resumir, adoptando supuestamente el mismo procedimiento que utilizó para su Historia de Oriente $(1940)^{3}$, de algún modo intenta legitimar las intervenciones fuertemente ideológicas sobre la exposición. Se trata de una apropiación que continúa la revisión de la tradición romana desarrollada en textos anteriores, sobre todo en el mencionado Catilina: contra la oligarquía (1935), y que también podrá advertirse en textos posteriores como Historia de la argentina 15151957 (1957) y La historia falsificada (1960). En efecto, para Palacio, como para otros nacionalistas, la historia del auge y la caída de Roma provee un verdadero modelo histórico y de acción política (es, de hecho

\footnotetext{
${ }^{2}$ Para una delimitación del "nacionalismo de derecha", cfr. Lvovich 2006.

${ }^{3}$ La Historia de Oriente (1940) fue escrita por Palacio para la misma colección de la editorial Albatros en la que se publicó la Historia de Roma. Y se trata -a diferencia de la Historia de Roma- de un verdadero resumen escolar, sin mayores inflexiones ideológicas.
} 
una de las fuentes del tópico de la decadencia, caro a la imaginación revisionista, tal como lo ha analizado Halperín Donghi [2005]).

No abundaremos aquí sobre la trayectoria de Palacio, desde las vanguardia martinfierrista hasta el peronismo, pasando por su conversión al catolicismo, el nacionalismo anti-yrigoyenista del periódico $L a$ Nueva república, el apoyo y la posterior desilusión con el golpe de Uriburu, el filofascismo en los '30, para lo cual el lector puede remitirse a la detallada semblanza de Sanjurjo de Driollet (2002); digamos solamente que en esta trayectoria la invocación del pasado romano ocupó siempre un lugar fundamental, como forma de crítica a las "abstracciones" del utopismo ilustrado y revolucionario. De este modo, en Teoría del Estado de 1949, texto que cita los nombres, entre otros, de Pareto, Sorel, Maurras, Burke, y de "Karl" Schmitt (Jorge Dotti tiene páginas interesantes sobre la misreading palaciana del jurista alemán ${ }^{4}$ ), el ejemplo romano sirve, sobre todo, para articular una teoría política que se opone al "idealismo del siglo XVIII". Recordemos que Palacio siempre recusó la supuesta pérdida de objetividad que para el implicaba la modernidad. De allí que, en metafísica Palacio haya optado, contra el "subjetivismo" moderno, por el realismo tomista; en arte, por una teoría de la belleza inspirada (entre otros) en Jacques Maritain, que se supone refutaría al "subjetivismo kantiano", al "romanticismo" y a la "irracionalidad" del "arte deshumanizado" de la que hablaba Ortega; y en términos políticos, por una perspectiva a la vez "racionalista" y "naturalista" que para él se opondría claramente al utopismo dieciochesco y al moderno "demoliberalismo". Es a partir de este horizonte que Palacio relee el pasado clásico, realzando toda una serie de valores que deberían ser transmitidos en la instancia pedagógica.

Confluyen entonces en la Historia de Roma, por un lado, las tradicionales preocupaciones moralizantes, siempre estrechamente conectadas a la enseñanza del latín y la cultura greco-romana (Waquet 1998), con una clara orientación nacionalista, en el sentido, bastante cercano al corporativismo fascista, en que Palacio entendía el término por aquellos años. Es notable que estas incrustaciones ideológicas estén presentes en la Historia de Roma pero no en la Historia de Oriente, como si el objeto que realmente el nacionalismo palaciano se quisiera anexar como propio, o convertir en tema de meditación, fuera más el "pasado grecolatino", entendido como "origen de Occidente", que la "antigüedad" en su conjunto 5

Ahora bien: lo primero que salta a la vista, en esta exposición de la historia de Roma, es la centralidad que Palacio le otorga a las disputas sociales entre patricios y plebeyos. Esta lectura de las luchas sociales de Roma se interpreta según la mirada revisionista, es decir a partir de una tensión entre "oligarquía" y "pueblo", que deriva en la concomitante necesidad de un "cesarismo" fuerte. En esta línea se inscribe el elogioso retrato de los tribunos de la plebe, o la lectura de las leyes de las doce tablas como reformas "populares" que promovían mejoras sociales. Asimismo, el viejo argumento de la decadencia del mos maiorum es leído en clave antioligárquica. Este párrafo Palacio podría haberlo aplicado con pocos cambios a la realidad argentina:

Con las conquistas y el desarrollo del comercio, el estado social cambia fundamentalmente. En el espacio de una generación, aparece un poder nuevo, que relega a un segundo término la propiedad raíz. Es el capital mobiliario, la acumulación de riqueza proveniente del comercio y la especulación. El capitalismo se convierte poco a poco en el principal poder social y su acción provoca el empobrecimiento de los pequeños propietarios, la desparición paulatina de la clase media, la aparición de un proletariado famélico y el ahondamiento de las diferencias sociales y del encono de los pobres contra los ricos. (Palacio 1939: 74-5)

Digamos por lo demás que la escritura de manuales se inscribe en las intervenciones en política cultural que Palacio desarrolló a lo largo de toda su vida y en diversos ámbitos (también cuando ocupó el cargo de diputado del Congreso de la Nación, a despecho de una leyenda tenaz que le adjudica un autoimpuesto silencio en el recinto legislativo a partir de $1946^{6}$ ). Entre esas actividades destaca la presidencia a partir de 1946 de la Comisión Nacional de Cultura; bajo su gestión se comenzó a editar la Guía quincenal de la

\footnotetext{
${ }^{4}$ Cfr. Dotti 2000: 167-170.

${ }^{5}$ Para el modo en que los nacionalistas concebían a "Occidente" en contraste con "Oriente", cfr. Bergel 2015:291-324.

${ }^{6}$ Es notable que incluso un lector tan agudo como Dotti tomara en serio esta difundida leyenda y titulara las páginas referidas a Palacio en Carl Schmitt en la Argentina "Mutus in foro: el caso de Ernesto Palacio" (Dotti 2000:167). La leyenda sobre el "silencio de Palacio" puede leerse una simplificación de la conflictiva relación que el intelectual Palacio tuvo con su rol de gestor de políticas culturales: Palacio fue nombrado en 1946 por Perón como presidente de la Comisión Nacional de Cultura y dimitió del cargo en 1947, entre otros motivos, a causa de la polémica en torno a la elección de los ganadores de los premios nacionales, luego de lo cual fue raleando sus apariciones e intervenciones en la cámara de diputado. Cfr. Quattrochi-Woisson 1995: 255-269. Asimismo, para la actuación parlamentaria de Palacio, cfr. Palacio 1999.
} 
actividad artística e intelectual argentina, y se impulsó la reforma de la ley 11.723 de Propiedad Intelectual, que reglamentaba en su artículo 23 la propiedad de los derechos de las traducciones, tema crucial para las editoriales nacionales ${ }^{7}$. Las clásicas parecen haber ocupado un lugar destacado en la forma en que Palacio concebía sus invertenciones en política cultural. Así se advierte, por ejemplo, en "El problema educacional", una conferencia pronunciada en el Centro Universitario Argentino, entidad peronista que había sido fundada entre otros por el diputado Ricardo C. Guardo y que se autodenominaba "tribuna de la revolución...y del pensamiento vivo de Perón, su jefe" (Guardo en Palacio 1948:7). El texto de Palacio fue editado en 1948 como parte del volumen titulado, justamente, Tribuna de la revolución, que recopilaba las conferencias dictadas en el Centro Universitario por diversas figuras, entre ellas el mismo Perón. En esta conferencia, leída en el contexto de la defensa de la política universitaria del gobierno peronista, Palacio retomaba una conferencia anterior, "Humanismo y folklore", pronunciada en la Universidad de Tucumán, en la cual exponía su visión del humanismo, según la cual legado clásico y folklore son fuentes de una misma sabiduría. Esta convergencia entre tradición grecolatina y saber popular, argumentaba Palacio, se opone al pensamiento incompleto del intelectual "ateneísta" o "liberal" (nombres apenas enmascarados para referirse al personal de la universidad "reformista", bajo ataque en ese momento $\left.{ }^{8}\right)$ :

Es un hecho probado que las naciones occidentales que han contado en la época contemporánea con elencos de estadistas verdaderamente prácticos, son las mismas que no renovaron sus métodos tradicionales de educación y que continuaron formando a sus clases dirigentes con Homero y Virgilio. En un discurso pronunciado en enero de 1926 en la Classical Association, de Londres, Sidney Baldwin, varias veces primer ministro, confesó paladinamente su deuda con los clásicos, consistente en la adquisición de the historical sense. No creo aventurado afirmar que la superioridad política inglesa se debe ante todo a que su tipo corriente fué el scholar de Oxford o de Cambridge. Lo mismo puede decirse de Alemania, en lo que se refiere a los directores del pensamiento, inspiradores de hombres de acción. En otras naciones occidentales, en cambio, los puestos dirigentes del pensamiento y la política cayeron en manos de los productos de la educación utilitaria: el tipo corriente no fue el scholar, sino el intelecto 'ateneísta', profesional liberal o escritor formado en redacciones, semiculto atiborrado de lecturas incontroladas. Los resultados tenían que ser la ideología vacua, la improvisación quimérica, la confusión, el caos social, la guerra civil.

[...]

El actual movimiento en pro de una educación humanista es una reacción contra los resultados intelectuales y morales de esa experiencia desgraciada [de la educación utilitaria].

[...] [E]l humanismo es, antes que la enseñanza de tal o cual disciplina determinada, una actitud del espíritu. ¿En qué consiste? No conozco una definición más comprensiva que la consignada por Walter Pater al final de su ensayo sobre Pico della Mirándola [sic]. 'La esencia del humanismo -escribe- consiste en creer ... que nada de lo que haya interesado alguna vez a hombres y mujeres vivientes puede perder del todo su vitalidad: ni los idiomas que hablaron, ni los oráculos ante los que alzaron sus voces, ni los sueños que soñaron, ni nada que los haya apasionado alguna vez y les haya costado tiempo y celo.' Esta creencia en la unidad fundamental del espíritu humano, que nos lleva a sentir, a concebir la cultura como una continuidad y no como una serie sucesiva de negaciones, es lo que se trata de recuperar. Ella nos mueve a volvernos con amor y humildad hacia nuestros orígenes para beber, en la tradición heredada, la experiencia secular de la especie: actitud de ánimo radicalmente opuesta a la que inspiró los principios en que se funda la educación utilitaria.

Ahora bien, esa experiencia secular de la especie -y más precisamente, de nuestra civilización occidental- se encuentra, sin duda, encerrada en los mitos, las máximas, las observaciones, las reflexiones y las imágenes de las obras maestras de la literatura clásica. Y el conocimiento de ésta, así como los idiomas en que se escribió, tiene que comunicarnos necesariamente una idea justa sobre lo que somos [...] Pero esta experiencia secular no se encuentra solamente en las obras clásicas. Se encuentra también, como tradición, en la boca del pueblo, transmitida de generación en generación, en forma de leyendas, fábulas morales, refranes, supersticiones y canciones. En una palabra, en el folklore [...]

Nosotros, ciudadanos de un país que cayó en una profunda postración, bajo la dirección de los intelectuales de tipo ateneísta y los profesionales liberales, fuimos salvados por los soldados y los obreros, es decir por gente que no tenía patente de intelectual, pero que demostró en el proceso una mayor comprensión de las

\footnotetext{
${ }^{7}$ Para la discusión de ley 11723 impulsada por la CNC, cfr. Giuliani 2018: 149-168. Para la labor de Palacio con la Guía quincenal. cfr. Lifschitz 2010.

${ }^{8}$ Sobre el conflicto con la universidad reformista, cfr. Pronko 2004.
} 
necesidades de la Patria, una inteligencia práctica más aguda y, en suma, una mayor cultura que los productos de la escuela y de la universidad. (Palacio 1948: 102-106)

Según esta argumentación, la tradición, que implica el conocimiento de los "idiomas", "oráculos" y "sueños" de otras culturas, se opone a la "educación utilitaria", que en otra parte de la argumentación se adjetiva asimismo como "europeísta" (nótese por lo demás que esta crítica a la especialización, un recurrido tópico del anticapitalismo romántico, va acompañada aquí de la valoración positiva de "los directores del pensamiento"- alemanes, lo cual puede interpretarse como un guiño hacia los intelectuales de la "revolución conservadora" alemana y hacia el fascismo en términos generales). "La ideología vacua", "el caos", "la improvisación quimérica", "la confusión", "la guerra civil", se relacionarían con la ausencia de esa formación humanística que, según se lee en El espíritu y la letra, texto publicado en 1936, se correspondería a "la época jubilosa de expansión de las repúblicas y a las monarquías conquistadoras" (Palacio 1936:49). Este argumento implica la coexistencia de dos tendencias, en principio contradictorias: por un lado, la continuidad que supone un humanismo entendido como "tradición heredada" y "experiencia secular de la especie", continuidad que sugiere una cierta apertura hacia lo extranjero; por el otro lado, la diferencia entre las naciones, surgida de las jerarquías que produce la lucha por la "superioridad política".

Una visión agonística de las relaciones internacionales literarias, de inspiración geopolítica, entonces, y una apelación a la continuidad cultural de "Occidente", elementos estos que encontramos, con variantes, en otros intelectuales nacionalistas, como Carlos Ibarguren, Juan E. Carulla o Manuel Gálvez. Palacio expresa un momento de altísima confianza en el poder de la "tradición clásica", cuando estos discursos sobre el "pasado de Occidente" son enunciables desde una posición que aspira a ser dominante en el campo político y cultural. Es notable, en este sentido, la relación que se establece en este pasaje entre literatura clásica y "superioridad civilizatoria" (nótese la amplitud de lecturas del humanismo palaciano, nutrido de Pater y Pico, mucho más rico que el que encontramos en exponentes típicamente clerofascistas como Gustavo Franceschi, Julio Meinvielle o Jordán Bruno Genta).

Ahora bien: este planteo en relación a las clásicas y la constitución de la cultura nacional se inscribe en la problemáltica más amplia de las traducciones en la cultura argentina. Es decir: frente a una "cultura liberal" que Palacio caracteriza en "El problema educacional" como "obediente al espíritu de la oligarquía", signada por una "gran insensibilidad para lo auténticamente popular", "enciclopédica", "europeísta", presa de "un escepticismo radical", propia de "hombres desarraigados" se impondría un retorno a la "realidad de la patria". Lo notable es que este retorno a lo nacional se hace también a partir de una apropiación de las tradiciones extranjeras, tal como se advierte en el párrafo que hemos citado, en cual se postulan como modelos las tradiciones inglesa y alemana. Lejos de negar la instancia de la traducción (tal es la sugerencia de la famosa burla de Borges contra Palacio en "La muerte y la brújula": Ernesto Palacio/Ernst Palast traduce, pero no sabe que traduce), Palacio más bien acepta la inevitabilidad de la traducción, pero elabora una serie de regulaciones imaginarias, a los efectos de postular que esa traducción es el pasaje de lo mismo a lo mismo, es decir, el pasaje de una expresión de ese "Occidente" esencial a otra expresión de ese mismo "Occidente" esencial. Si en el origen de la "cultura occidental" estaba "Homero", en el final del despliegue de la "cultura nacional" argentina, también estaría "Homero" -un "Homero" que, por lo demás, supone de forma lugoniana Palacio, ya puede escucharse en las tradiciones folkóricas argentinas (de forma lugoniana pero también peronista-: porque el mismo Perón, y este es un tópico que se encuentra en varias de sus intervenciones públicas, hacía descender a la cultura argentina del mundo grecolatino, sin que por esto podamos suponer, obviamente, que la perspectiva sobre la cultura de Perón, o de los diversos intelectuales que adhirieron al régimen peronista puedan reducirse a este posicionamiento en particular ${ }^{9}$ ). En este pasaje lo de lo mismo a lo mismo, la heterogeneidad que necesariamente conllevan las operaciones de traducción e importación debe ser tolerada como una suerte de mal necesario, hasta la constitución de esa cultura nacional finalmente orgánica en la que también se expresará "Occidente". Es un argumento caro a los escritores del nacionalismo de derecha, que podemos encontrar tanto en el Gálvez fascistizante de los '30 como en el

\footnotetext{
${ }^{9}$ Por ejemplo en su discurso de repción del título de doctor "honoris causa" por su obra en favor de la cultura nacional: "Pero cuando una Nación recupera su ser nacional; cuando un país se reencuentra después de haberse diluído en tanteos triviales e influencias extrañas a su tradicional modo de ser, la cultura se convierte en fuerza de inimaginables proyecciones. [...] A la cultura directamente heredada, a nuestro acervo tradicional, he de referirme esta noche. Pero conviene que dedique un breve espacio al origen de nuestro saber: la cultura greco-romana, de la que debemos ser y somos continuadores, y que fué en su tiempo inicial síntesis de las que florecieron anteriormente como la caldea, la persa y la egipcia, culturas que se desvanecieron en el tiempo posterior a Alejandro para ser absorbidas definitivamente por las formas helenisticas.” (Perón 1947:19).
} 
Palacio de los primeros años del peronismo: como dice Carlos Ibarguren en su intervención en la Séptima Conversación de la Organización de la Cooperación Intelectual de la Sociedad las Naciones, organizada aprovechando la presencia en la Argentina de los escritores participantes del XIV Congreso Internacional de los P.E.N. Clubs, la Argentina es "todavía" -subrayo el adverbio- "tierra de aluvión"10. Pero esa heterogeneidad es un síntoma transitorio de inmadurez, que aporta los materiales para que surja una literatura "auténticamente" argentina - una "literatura argentina" que, parecen suponer los nacionalistas del '30 y el '40 (es decir, contemporáneos de Borges, Arlt y Martínez Estrada), todavía no existe.

Este modelo explicativo, al que suelen acudir los nacionalistas para ordenar su discurso en torno a la relación entre "literatura argentina" y a lo que entienden por "literatura universal" (en realidad, más bien europea-occidental), se basa en una oposición tajante entre la supuesta organicidad y completud de las viejas culturas europeas, y la hibridación de la "Babel" argentina ${ }^{11}$. Es decir, una oposición entre culturas que son traducidas en el extranjero (que practican la ex-traducción), y culturas traductoras (que practican la intraducción). Desde esta perspectiva, las literaturas nacionales europeas serían entidades acabadas y completas, que "expresan" una determinada nacionalidad; mientras que la literatura argentina, en tanto literatura "joven", "inmadura", estaría amenazada por la heterogeneidad, amenaza que persistiría hasta que se consume la expresión de la "cultura nacional", es decir, hasta que a partir de los materiales traducidos del "Occidente europeo", surja el "Occidente americano". La heterogeneidad del estado de traducción, se disolverá, piensan los nacionalistas, para abrir paso a un futuro orgánico: "Occidente", está al principio y al final de este movimiento. En este proceso, las clásicas ocupan un lugar central, como una suerte de garantía y caución de que la operación de traducción no habrá de extraviarse en la heterogeneidad (la heterogeneidad oriental, indígena, comunista, latinoamericana, sajona, o la heterogeneidad venida de las formas "inadecuadas" o "antinacionales" de la inmigración o de la cultura popular, como el tango: el otro a excluir de la "herencia occidental" cambia según los distintos planteos políticos y los posicionamientos coyunturales). Las clásicas son, según esta perspectiva, el operador que garantiza la identidad última de "Occidente", y su rol central se relaciona, precisamente, con el reconocimiento de que la cultura argentina está "en situación de traducción". Lejos pues de un desconocimiento de la "situación de traducción", el nacionalismo más bien intenta encauzar a la traducción por los andariveles de una cierta organicidad identitaria. Palacio, por caso, mal podía desconocer "el estado de traducción" de la cultura argentina, siendo que el mismo tradujo para diversas editoriales (entre ellas Sur) e impulsó, como ya hemos dicho, la reforma de la ley de Propiedad Intelectual, cuyo artículo 23 trataba, precisamente, sobre la protección de los derechos de traducción. En este contexto de reconocimiento del hecho de la traducción y la importación cultural debe inscribirse la afirmación identitaria de "Occidente" y la consecuente importancia que Palacio le otorga al pasado clásico en intervenciones pedagógicas como la escritura de la Historia de Roma. Estamos pues, en un momento intenso de lectura de los clásicos por parte de las derechas argentinas que, como veremos

10 "En estos últimos tiempos, sobre todo después de la gran guerra, se ha desarrollado en los pueblos, tanto europeos como americanos, un acentuado sentimiento nacionalista que no se limita al terreno económico, sino que se extiende al cultural. Los escritores y poetas argentinos que recibieron la literatura europea y la reflejaron como un espejo sin crear obras que se dieran formas originales o contenido nuevo a las creaciones locales, están hoy agitados por una inquietud que creo será fecunda. Ellos escudriñan ahora nuestro ambiente, nuestra vida urbana y rural, nuestra alma no definida aún. El caudaloso contingente extranjero, heterogéneo y cosmopolita ha cambiado las características de gran parte del pueblo criollo. Esta tierra es todavía de aluvión; fértil, pero sin la consistencia ni la fisonomía que dan las tradiciones y la historia. Con verdad dijo Paúl Groussac que no es solamente una argentina nueva, sino también un argentino distinto el que aparece a la vuelta de cada generación.

No tenemos todavía una cultura propia; pero en vez de recibir hoy la europea con pasividad, buscamos, con ansia encontrar en nosotros mismos nuestra peculiar expresión espiritual. Cuando logremos plenamente ese hallazgo habremos creado entonces un aporte nacional nuevo que influirá en la literatura mundial." (Ibarguren en AA.VV 1937a:196-7).

${ }^{11}$ La intervención de Manuel Gálvez en el XIV congreso de los P.E.N. Clubs, celebrado en 1936 en Buenos Aires, es elocuente en este sentido: "Hubiéramos deseado, los escritores argentinos, ofrecerles a ustedes, para su breve residencia en nuestra patria, una ciudad de arte o de bellezas naturales, como las que hay en todos los países del mundo. Pero Buenos Aires, dinámica, fuerte, rica, es una ciudad sin encantos. No tiene monumentos milenarios no aun seculares. No tiene la belleza estética y espiritual de unas ruinas que pueblen el ambiente con las sugestiones y las melancolías del pasado. [...]Su valor emocional es casi nulo. Buenos Aires no nos habla al alma, a hombres que viven para el espíritu. Es la capital de un pueblo que ha vivido poco, que ha sufrido poco, y que ha pensado poco, y el gran arte no es sino la transmutación en belleza del dolor y del pensamiento humanos. [...] Nosotros los argentinos, como los demás latinoamericanos, debemos a las culturas extranjeras todo lo que somos. [...] Nosotros no tenemos, ni tendremos en mucho tiempo, una cultura propia. Somos un pueblo cosmopolita, una moderna Babel. La Argentina se está construyendo con retazos de numerosos pueblos. Se ha dicho que tal vez esta falta de característica sea precisamente nuestra característica. Pero yo diría, también, que somos un pueblo de grandes ambiciones de universalidad. Ya hay algo universal en Buenos Aires, y hasta pudiera decirse que, por algunos aspectos materiales de nuestra vida, vamos en camino de definirnos coma una muestra de lo que será la humanidad de Occidente. Pero en lo espiritual no estamos todavía maduros. Aun no hemos dado al mundo lo que alguna vez podremos darle. Nuestro mensaje permanece oculto, y ni nosotros mismos lo conocemos. Pero presentimos que existe. Y muy probablemente no será el mensaje de esta sóla patria, sino el de la América latina." (Gálvez en AA.VV. 1937b:263-4). 
encontrará en las siguientes décadas algo así como un punto de exasperación, para diluirse luego a partir del retorno a la democracia en 1983.

\section{Disolución del uso de la referencia clásica}

Quizá sea interesante preguntarse por el lugar que tiene este uso de la tradición clásica por parte de Palacio y los otros nacionalistas del ' 30 y '40 en la historia de larga duración de las culturas y los discursos de las derechas argentinas. Digamos en principio que esta asociación entre clásicas y derechas no fue una invariante, sino un fenómeno que, con desvíos y anfractuosidades, parece haber emergido en los '20, se continuó hasta la dictadura de 1976-1983, y se disolvió en los años del retorno a la democracia. En efecto: desde nuestra perspectiva en 2018, quizá resulte sorprendente que el mundo grecolatino haya sido un objeto tan central en la disputa ideológica de las derechas. La emergencia de esta centralidad del humanismo clásico se debe, me parece, a varios factores: un cierto prestigio decimonónico de las humanidades clásicas, no del todo perdido todavía; la pregnancia de un cierto imaginario cultural, que asociaba pedagogía de la cultura clásica y elitismo; la recatolización de la cultura iniciada agresivamente por la Iglesia desde los años '20 y aún antes, como respuesta a las pedagogías liberales y de la izquierda (recatolización que se apoyaba en el humanismo cristiano, que recurría a un cierto recorte del pasado grecolatino); cierta lectura tradicionalista y anti-iluminista del mundo clásico por parte del discurso contrarrevolucionario, que pasó a las derechas antiliberales, a los ultranacionalismo y al fascismo.

Por lo demás, debemos notar que en esta revalorización del modelo clásico, Palacio representa un punto de cierto equilibrio o aglutinación. En los textos palacianos coinciden, con cierta originalidad elementos diversos: modelos maurrasianos y nacionalistas europeos, que intentaban una lectura tradicionalista pero "racionalista" del pasado clásico -no olvidemos la recusación que la Action Française hacía del romanticismo-; el humanismo cristiano de los Cursos de Cultura Católica y de la revista Criterio; la apropiación distanciada de la estetización de la violencia en clave "augustal" o "romana" que practicaba el fascismo. A lo cual debe sumársele un indiscutible talento de polemista para hacer entrar a los clásicos en la discusión política más contemporánea; de este modo, por ejemplo, en el Espíritu y la letra (1936) Palacio presenta, con fuertes acentos fascistas, a Plutarco como un modelo pedagógico que realza el "espíritu guerrero" y el "interés militante por la cosa pública", y que se opone a "nuestra civilización en decadencia" (Palacio 1936:97-98).

Ahora bien: ¿por qué se disolvió este uso de los clásicos por parte de las derechas?

Para responder a esta pregunta, es necesario antes introducir una breve puntualización sobre el estudio de las "derechas" y el "nacionalismo" (dos objetos que, si bien tienen zonas de superposición, de ningún modo pueden ser considerados equivalentes) en la Argentina. Una puntualización que implica una discusión con algunas interpretaciones historiográficas en torno a la génesis de la violencia de estado en el siglo XX argentino, que parecen atribuirle un signo excuyentemente antiliberal. Federico Finchelstein, por ejemplo, en Fascismo transatlántico (2010) y en Los orígenes ideológicos de la guerra sucia (2016), establecece de forma teleológica una lectura que liga fenómenos que van desde el nacionalismo desde el '30 hasta la dictadura 1976-1983. Dentro de esta lectura, autores como Ernesto Palacio (incluso el forjista Raúl Scalabrini Ortiz) son apenas precursores del personal intelectual de la dictadura militar que comenzó en 1976. Considero que las críticas que podrían hacérsele a Finchelstein son similares a las que ha merecido la polaridad lumières/anti-lumières propuesta por Zeev Sternhell para comprender el pensamiento europeo entre los siglos XVIII y XX: básicamente, ambas lecturas reducen la complejidad de los fenómenos históricos apelando a la teleología y la unicausalidad. Si para Sternhell la causa fundamental del fascismo es el irracionalismo anti-ilustrado, que ganará fuerza en los ultranacionalismos de fin de siglo XIX y tendrá su eclosión devastadora en los '30, para Finchelstein la violencia de estado argentina parece ser el resultado de la expansión de un fascismo y/o nacionalismo ajenos al programa liberal, un "irracionalismo" antiprogresista, anti-universalista y esencialmente anti-intelectual del cual es expresión el "populismo peronista" 12 . 
Esta lectura es, por lo menos, sesgada. Como demuestran las investigaciones de Sergio Morresi y Martín Vicente, entre otros, el universo de las derechas tiene una duración mucho más larga en términos temporales que el llamado "nacionalismo de derecha", y una latitud que desborda las expresiones más connotadas de un supuesto fascismo "típico" (corporativismo, populismo, palingenesia nacional, etc.) que tendría su modelo en la Europa de entreguerras. En ese universo de las derechas argentinas se inscriben diversas vertientes del liberalismo, que se remontan al siglo XIX y continúan en el siglo XXI. Pero una lectura de "larga duración" implica que las derechas argentinas no deben ser leídas solamente desde la continuidad, sino también en términos de ruptura y multipolaridad. Es evidente que en el universo plural, a menudo contradictorio, de las derechas se dio el pasaje paulatino de un modelo nacionalista, de acentos más bien maurrasianos o franquistas, a un modelo liberal-conservador, pasaje que ya apuntaba hacia la implantación del "neoliberalismo" de los años '90. En este pasaje, como ha demostrado Paula Canelo (2008), el "Proceso de Reorganización Nacional", con su personal liberal y nacionalista, fue una suerte de punto de inestable equilibrio.

Y es este pasaje, desde mi punto de vista, uno de los motivos fundamentales de la declinación del uso de los clásicos por parte de los discursos de la derecha, es decir, el corrimiento de la tópica y las referencias grecolatinas hacia los bordes, la periferia de estos discursos. Este eclipse de la referencia clásica es otra consecuencia del acrecentamiento de la importancia del saber gubernativo, técnico y administrativo liberal, que gana espacio en el mundo de las derechas por sobre el humanismo cristiano integrista y reaccionario en términos generales. Si quisiéramos resumir de forma apurada este movimiento, diríamos: de Edmund Burke a Friedrich Hayek, de Franco a Tatcher, de Charles Maurras a Ayn Rand.

Tres se me ocurren que son los síntomas más elocuentes de esta disolución del uso del saber clásico en el universo de las derechas:

1. Cierto uso exasperado de este saber clásico, por parte de la ultraderecha a los efectos de legitimar la necesidad de una violencia purificadora. Este uso tuvo uno de sus momentos más álgido, obviamente, durante los '70, con personajes como el latinista y profesor de la Universidad Nacional de la Plata, figura fundacional de la Concentración Nacional Universitaria (CNU), Carlos A. Disandro, cuya radicalización se verificó tanto en el campo ideológico como en el de la acción directa. El sedevacantista Disandro es quizá el único profesor de clásicas con actuación destadacada en el rubro parapolicial ${ }^{13}$. Otro excelente ejemplo de esta exasperación de los usos de los clásicos es Jordán Bruno Genta, a la vez propalador de las doctrinas de seguridad nacional e ideólogo ligado a las fuerzas armadas, y lector (no muy sutil, por decirlo de algún modo), de la filosofía griega ${ }^{14}$. Este doble perfil se advierte en su bibliografía, que combina títulos como Guerra contrarrevolucionaria (1963) y El filósofo y los sofistas (1949). Después del retorno a la democracia este uso exasperado de los clásicos subsistirá residualmente en diversas publicaciones de la extrema derecha, como la revista Cabildo ${ }^{15}$.

2. El aislamiento de la referencia clásica en ámbitos que no tienen mayor presencia en la discusión cultural o universitaria de más amplio alcance. Expresión de esta tendencia puede considerarse una empresa como la Historia de la filosofía en la Argentina, 1600-2000 de Alberto Caturelli, un recorrido en clave tomista por la filosofía argentina, editada en el año 2001. Esta obra, por lo demás no carente de interés en tanto recapitulación de un cierto modo de entender la filosofía, ingresó en la currícula de algunos programas confesionales, aunque su aparición fue mayormente ignorada por los centros de legitimación del campo intelectual argentino. Este aislamiento se da en simultáneo con la disminución, a partir de los '80, del ritmo de publicación o el cierre de las editoriales nacionalistas de derecha como Dictio, Huemul, Gladius, La Hostería Volante, fenómeno que acompaña la desarticulación de toda una red intelectual (con sus contactos con la política $\mathrm{y}$, a menudo, con las fuerzas armadas). Las obras de Julio Meinvielle, Juan R. Sepich o de Ignacio Braulio Anzoátegui pierden sus editores, dejan de estar activas en la discusión cultural, se convierten en una suerte de

fascismo? ¿Cómo y por qué estos regímenes aparecieronen un país que 'había nacido liberal'?” (Finchelstein 2016: 21-22). Nótese la oposición absoluta que construye Finchelstein entre "liberalismo" por un lado, y "fascismo" por el otro. Contra esta interpretación unilateral cfr., entre muchos otros, los trabajos de Vicente y Canelo citados en este trabajo. Asimismo, para un relevamiento y una contextualización de las posiciones autoritarias de algunos actores del heterogéneo bloque antiperonista en las décadas 1940 y 1950, cfr. Nállim 2014. Asimismo, para una perspectiva del vínculo de los intelectuales con el peronismo bastante más matizada que aquella que deja traslucir Finchelstein, cfr., entre otros, Fiorucci 2011.

${ }^{13}$ Sobre Disandro cfr. Carnagui 2015.

${ }^{14}$ Sobre Genta, cfr. Aguiar da Costa 2012.

${ }^{15}$ Para la trayectoria de Cabildo en los años del retorno a la democracia, cfr. Grinchpun 2018. 
resto arqueológico. Incluso pueden ser leídas de manera snob -el adjetivo no pretende ser peyorativo, todo lo contrario- por sectores ligados a la izquierda y/o a cierta modernidad crítica, que encuentran en algunas escrituras reaccionarias y/o integristas formas de heterodoxia atractivas, pasibles ser productivizadas a partir del distanciamiento que provee la lectura desde un nuevo contexto (Christian Ferrer lee, edita y comenta al mencionado Anzoátegui, por ejemplo, a quien por su parte Horacio González llamó "el fascista que ríe" ${ }^{16}$ ). Por lo demás, otro síntoma de esta disolución de la referencia clásica, es el hecho de que el libro católico para el gran público parece haber abandonado el discurso filósofico o doctrinal más duro, para acercarse a otros formatos editoriales, como efecto de cambios culturales generales y en la propia Iglesia. A diferencia de los tiempos de los Cursos de Cultura Católica, ni las élites ni el lectorado católico parecen demasiado interesadas en leer las quaestiones de Santo Tomás o en desentrañar la Civitas Dei de San Agustín. Estos autores han quedado casi enteramente en manos de especialistas universitarios.

3. Un uso superficial, de prestigio, de los clásicos para legitimar la defensa de posiciones liberalconservadoras. Tópicos como la "decadencia", "pan y circo", o la transgresión al mos maiorum, vuelven una y otra vez en los discursos de los intelectuales liberal-conservadores ${ }^{17}$. Un buen ejemplo de este uso ostentatorio de la referencia clásica podemos encontrarlo en la figura de Jaime Perriaux, un idéologo de peso en las políticas de la dictadura 1976-1983, quien de hecho inventó el nombre de "Proceso de Reorganización Nacional" (Vicente 2013: 4; cfr. también Morresi 2010). Perriaux era discípulo de Ortega y Gasset ${ }^{18}$, y publicó una rudimentaria historia del pensamiento nacional imaginada a partir de la numerología, Las generaciones argentinas, editada por Eudeba en 1970, es decir en el año en que Onganía se ve obligado a cederle el poder a Levingston. Una reseña sobre la trayectoria de este ideólogo en la revista Vigencia de la Universidad de Belgrano, explica que "Perriaux habla, lee y escribe fluidamente el francés, el inglés, el alemán, el italiano, el portugués, el latín y el griego" (Vigencia, N³, 1977 citado en García Lupo 2006: 292). El elogio obsecuente intenta sumar el dominio de la tradición clásica (bizarramente imaginado aquí como un "hablar fluido el latín y el griego") a la construcción del prestigio. Un segundo ejemplo lo encontramos en otro ideólogo de la dictadura, Ricardo Zinn ${ }^{19}$, quien en La segunda fundación de la república (1976) retoma la imaginería splengleriana sobre la decadencia -cuyo modelo es Roma- para explicar las causas de ese "populismo" al que le habría puesto fin la dictadura militar. En 4 años después de la segunda fundación de la república, segunda edición del texto, publicada en 1980, quizá para indicar la satisfacción por el curso de los acontecimientos, Zinn agrega como epígrafe la traducción de la conocida cita de De oratore 2.36 de Cicerón: "La historia es el testimonio de los tiempos, la luz de la verdad, la maestra de la vida, la mensajera del pasado" (Zinn 1980: 3). La tradición clásica se convierte en una mera marca de prestigio para autorizar el lugar de enunciación: Zinn todavía hablaba de "Circo y pan" (Zinn 1996: 71) en una nota del 21 de marzo de 1988 en El Cronista Comercial en la que criticaba la política del gobierno de Raúl Alfonsín. En los discursos liberalconservadores (que confluyen, sin solaparse del todo, con las preocupaciones de cierto humanismo cristiano reinterpetado en clave anticomunista), los clásicos devienen un elemento residual, un tópico que sirve para sancionar la necesidad de que haya "orden" y "libertad", o para fundar la defensa de los "valores de Occidente". Sería este uso de prestigio el que popularizaría un conocido periodista televisivo, quien lograría hacer de las etimologías erradas y las citas fragmentarias una marca de clase y de capital simbólico ante las audiencias de los medios masivos de comunicación ${ }^{20}$.

${ }^{16}$ Cfr. el estudio premilinar de Ferrer en Ignacio B. Anzoátegui. Vidas de muertos. Buenos Aires: Colihue-Biblioteca Nacional (colección Los raros), 2015.

${ }^{17}$ Para una definición de los intelectuales liberal-conservadores cfr. Vicente 2015.

${ }^{18}$ Para los orteguianos argentinos cfr. Vicente 2015: 94 y passim.

${ }^{19}$ Para una investigación sobre Ricardo Zinn y otras figuras del Grupo Azcuénaga, cfr. Vicente 2012.

${ }^{20}$ Sobre Grondona, véase el ocurrente texto de Tomás Abraham, "Los negritos del doctor Mariano Grondona", quien lo describe irónicamente como un "Sócrates" de la "Atenas electrónica": "En realidad [Grondona] tiene una ideología pendular. Cuando se siente fuerte y en su salsa, se vuelve romano y acude a su visión del Imperio, un imperio en el que los notables eran prestigiosos, las elites respetadas, los emperadores tenían vocación de filósofos -como Marco Aurelio-, un secretario del Líder oficiaba de inquieto pensador -como Séneca [...] consejero de Nerón-; un mundo en el que los patricios tenían sus riquezas y privilegios legitimados por la cultura, en el que las virtudes de generosidad, magnanimidad, el uso cultural de las riquezas -lo que el historiador Paul Veyne llama 'evergetismo'-, las relaciones de clientela de quienes donaban a la ciudad sus teatros Colones y Cervantes, sellaban dignamente el poder los ricos.

Cuando le llegan al Doctor las épocas de arrepentimiento, las que él llama de aprendizaje, todo este mundo feliz es sustituido por el reconocimiento de su condición humana y no tan sólo romana. Cuando alguna vocaciín imperial a la romana fracasa en la Argentina, entonces el 
Exasperación, aislamiento y conversión en marca de prestigio: tales parecen ser los modos en los que se manifiesta este eclipse de los usos de los clásicos grecolatinos por parte de las derechas. Debilitada o disuelta le relación de la tradición clásica con el discurso de las derechas nacionalistas o liberal-conservadoras, la lectura de los clásicos, a partir del retorno de la democracia, parece haber quedado, sobre todo, en manos del campo académico. Pero este fenómeno: la lectura de los clásicos por parte de los especialistas a partir de 1983, con sus efectos contradictorios y su aparente neutralización ideológica, una lectura que se refracta por las leyes parcialmente autónomas del campo intelectual, sobre todo universitario, forma parte de otra discusión y excede los límites de este artículo.

\section{Referencias bibliográficas}

AA.VV. (1937). Europa América Latina. Buenos Aires: Comisión Argentina de Cooperación Intelectual/Institut International de Coopération Intelectuelle.

AA.VV. (1937). XIV Congreso Internacional de los P.E.N. Clubs. 5-15 de septiembre de 1936. Discursos y debates. Buenos Aires: P.E.N. Club de Buenos Aires.

Abraham, Tomás (1995). Historias de la Argentina deseada. Buenos Aires: Sudamericana.

Aguiar da Costa, Betina (2012), "Una pedagogía de la guerra y la muerte. Genta. educador de una estética militar", en Actas de III Jornadas Nacionales I Latinoamericanas de investigadores/as en formación en eduación Instituo de Investigaciones en Ciencias de la Educación (IICE), 3 y 4 de diciembre de 2012.

Disponible en: http://iice.institutos.filo.uba.ar/sites/iice.institutos.filo.uba.ar/files/8-Perspectiva\%20histórica.pdf

Bergel, Martín (2015). El oriente desplazado: los intelectuales y los orígenes del tercemundismo en la Argentina. Bernal: Universidad Nacional de Quilmes.

Besoky, Juan Luis (2019), "De Maurras a Perón. A trajetória intelectual de Jaime María de Mahieu e sua influencia no nacionalismo argentino", en Ernesto Bohoslavsky, Rodrigo Patto Sá Motta, Stéphane Boisard (eds.). Pensar as direitas na America Latina. São Paulo: Alameda, pp. 483-503.

Bohoslavsky, Ernesto (2018), "La historia transnacional de las derechas argentinas en el siglo XX: ¿qué sabemos y qué podríamos saber?", Páginas. Revista digital de la Escuela de Historia de la Universidad Nacional de Rosario, año $10, \mathrm{~N}^{\circ} 24$, Septiembre-Diciembre de 2018, pp. 10-33.

Disponible en: http://revistapaginas.unr.edu.ar/index.php/RevPaginas/article/view/307

Canelo, Paula (2008), "Las 'dos almas'del Proceso. Nacionalistas y liberales durante la última dictadura militar Argentina (1976-1981)", Páginas. Revista digital de la Escuela de Historia de la Universidad Nacional de Rosario, año 1 - $\mathrm{N}^{\circ} 1,2008$, pp. 69-85.

Disponible en: http://revistapaginas.unr.edu.ar/index.php/RevPaginas/article/view/307

Carnagui, Juan Luis (2015). Nacionalistas, católicos y peronistas. Auge, afianzamiento y reconfiguración de la Concentración Nacional Universitaria (CNU), La Plata, 1955-1974. Tesis de doctorado defendida en la Facultad de Humanidades y Ciencias de la Educación de la Universidad Nacional de La Plata.

Disponible en: $\quad$ http://sedici.unlp.edu.ar/bitstream/handle/10915/53781/Documento completo.pdfPDFA.pdf?sequence $=3$

Caturelli, Alberto (2001). Historia de la filosofía en la Argentina, 1600-2000. Buenos Aires: Ciudad Argentina/Universidad del Salvador.

Devoto, Fernando (2006). Nacionalismo, fascismo y tradicionalismo en la Argentina moderna. Buenos Aires: Siglo XXI.

Dobry, Edgardo (2010). Una profecía del pasado: Lugones y la invención del "linaje de Hércules”. Buenos Aires: Fondo de Cultura Económica.

Dotti, Jorge Eugenio (2000). Carl Schmitt en la Argentina. Rosario: Homo Sapiens.

Finchelstein, Federico (2010). Fascismo transatlántico. Ideología, violencia y sacralidad en Argentina y en Italia, 1919-1945. Buenos Aires: Fondo de Cultura Económica.

Finchelstein, Federico (2016). Orígenes ideológicos de la "guerra sucia". Fascismo, populismo y dictadura en la Argentina del siglo XX. Buenos Aires: Sudamericana [Penguin Random House].

Finchelstein, Federico (2018). Del fascismo al populismo en la historia. Buenos Aires: Taurus.

Fiorucci, Flavia (2011). Intelectuales y peronismo, 1945-1955. Buenos Aires: Biblos.

García Lupo, Rogelio (2006). Últimas noticias de Perón y su tiempo. Buenos Aires: Ediciones B.

Giuliani, Alejandra (2018). Editores y política. Entre el mercado latinoamericano de libros y el primer peronismo (1938-1955). Temperley: Tren en Movimiento.

Doctor vuelve a los brazos del modesto carpintero de Galilea, se re conoce criatura de Dios. Pero en el año 1962 [año de la publicación de su libro Politica y gobierno] Grondona se siente en Roma..." (Abraham 1995: 166). Dice por su parte Rinesi: "Los argumentos de Mariano no ganan nada gracias a la mención de los autores: sólo Mariano gana con ello. Mariano no discute Aristóteles, ni Kant, ni Nozick. Ni siquiera usa sus fuentes. Las cita. Y luego baja [...] Es el catedrático, sin dejar de ser el periodista.” (Rinesi 1992: 30) 
Gramuglio, María Teresa (2013). Nacionalismo y cosmopolitismo en la literatura argentina. Pról. Judith Podlubne. Rosario: Editorial Municipal de Rosario.

Grinchpun, Boris Matías (2018), “'Trabajador, Rebélate'. Clase obrera y sindicalismo en la cultura política de las extremas derechas argentinas, 1983-9”, Historice, v. 9, N², pp. 113-135.

Halperin Donghi, Tulio (2005). El revisionismo histórico argentino como visión decadentista de la historia nacional. Buenos Aires: Siglo XXI.

Lifschitz, Laura (2010), “Guía Quincenal: la cultura como parte de un proyecto de gobierno”, en Claudio Panella y Guillermo Korn compiladores (comps.). Ideas y debates para la Nueva Argentina. Revistas culturales y políticas del peronismo (1946-1955). Volumen I. La Plata: Universidad Nacional de La Plata.

Loubet del Bayle, Jean-Louis (2001)[1969]. Les non-conformistes des années 30: une tentative de renouvellement de la pensée politique française. Paris: Éditions du Seuil.

Lvovich, David (2006). El nacionalismo de derecha. Desde sus orígenes a Tacuara. Buenos Aires: Capital Intelectual.

Maulnier, Thierry (1964). Cette Grèce où nous sommes nés. Paris: Flammarion.

Morresi, Sergio (2010), "El liberalismo conservador y la ideología del Proceso de Reorganización Nacional", Sociohistórica, n²7, pp. 103-135.

Disponible en: http://www.memoria.fahce.unlp.edu.ar/art_revistas/pr.4878/pr.4878.pdf

Nállim, Jorge A. (2014). Las raíces del antiperonismo. Orígenes históricos e ideológicos. Buenos Aires: Capital Intelectual.

Palacio, Ernesto (1948), "El problema educacional”, en AA.VV. Tribuna de la revolución. Conferencias (pról. de Ricardo C. Guardo). Buenos Aires: Ediciones Nueva Argentina/Centro Universitario Argentino, pp. 92-112.

Palacio, Ernesto (1936). El espíritu y la letra. Buenos Aires: Ed. Serviam.

Palacio, Ernesto (1939). Historia de Roma. Buenos Aires: Albatros.

Palacio, Ernesto (1940). Historia de Oriente. Buenos Aires: Albatros.

Palacio, Ernesto 1973 [1949]. Teoría del Estado. Buenos Aires: Eudeba.

Palacio, Ernesto (1999). Política y cultura. Pról. de Luis C. Alen Lascano. Buenos Aires: Círculo de Legisladores de la Nación Argentina.

Perón, Juan Domingo (1947). Discurso del Presidente de la Nación Argentina General Juan Perón pronunciado en el acto de homenaje tributado por las universidades argentinas al otorgársele el título de doctor "honoris causa” por su obra en favor de la cultura nacional. Buenos Aires: noviembre 14 de 1947.

Pronko, Marcela (2004). El peronismo en la universidad. Buenos Aires: Eudeba.

Quattrocchi-Woisson, Diana (1995). Los males de la memoria: historia y política en la Argentina. Buenos Aires: Emecé.

Rinesi, Eduardo (1992). Mariano. Buenos Aires: La Marca.

Sanjurjo De Driollet, Inés (2002), "Ernesto Palacio: del nacionalismo al peronismo", Historiografía Rioplatense, $\mathrm{n}^{\circ}$ 6, pp. 101-130.

Sverdloff, Mariano Javier (2017), "La tradición clásica y el nacionalismo argentino: un caso de transferencia cultural”, Circe, de clásicos y modernos N²1/2 (julio-diciembre 2017), pp. 55-72.

Vicente, Martín (2013), "Doble red: republicanismo y neoliberalismo en escala internacional a través de la última dictadura argentina. Actores, ideas, prácticas y debates", en Actas de XIV Jornadas Interescuelas/Departamentos de Historia. Mendoza: Departamento de Historia de la Facultad de Filosofía y Letras, Universidad Nacional de Cuyo.

Vicente, Martín (2015). De la refundación al ocaso: Los intelectuales liberal-conservadores ante la última dictadura. La Plata-Los Polvorines: Universidad Nacional de La Plata. Facultad de Humanidades y Ciencias de la Educación/Universidad Nacional de General Sarmiento/Universidad Nacional de Misiones.

Disponible en: http://www.memoria.fahce.unlp.edu.ar/libros/pm.406/pm.406.pdf

Vicente, Martín (2012), "Los intelectuales liberal-conservadores argentinos y la última dictadura. El caso del Grupo Azcuénaga", Kairos. Revista de Temas Sociales, Año 16, N² 29, Mayo de 2012.

Waquet, Françoise (1998). Le latin ou l'empire d'un signe, $X V I^{e}-X X^{e}$ siècle. Paris: Albin Michel.

Zinn, Ricardo (1976). La Segunda Fundación de la República. Buenos Aires: Pleamar.

Zinn, Ricardo (1980). 4 años después en la Segunda Fundación de la República. Buenos Aires: Pleamar.

Zinn, Ricardo (1996). Por una ética de la responsabilidad. Buenos Aires: Fundación Carlos Pellegrini. 